Tropical Journal of Pharmaceutical Research May 2017; 16 (5): 981-988

ISSN: $1596-5996$ (print); 1596-9827 (electronic)

(C) Pharmacotherapy Group, Faculty of Pharmacy, University of Benin, Benin City, 300001 Nigeria.

All rights reserved.

Available online at http://www.tjpr.org

Original Research Article

http://dx.doi.org/10.4314/tjpr.v16i5.3

\title{
Dissolution and permeation characteristics of artemether tablets formulated with two gums of different surface activity
}

\author{
Emmanuel $O$ Olorunsola ${ }^{1,2 \star}$, Partap G Bhatia ${ }^{3}$, Babajide A Tytler ${ }^{2}$, Musiliu $O$ \\ Adedokun ${ }^{1}$ and Michael U Adikwu ${ }^{4}$ \\ ${ }^{1}$ Department of Pharmaceutics and Pharmaceutical Technology, University of Uyo, Uyo, ${ }^{2}$ Department of Pharmaceutics and \\ Pharmaceutical Microbiology, Ahmadu Bello University, Zaria, ${ }^{3}$ Department of Pharmaceutics and Pharmaceutical \\ Microbiology, Usmanu Danfodiyo University, Sokoto, ${ }^{4}$ Department of Pharmaceutics, University of Nigeria, Nsukka, Nigeria
}

*For correspondence: Email: olorunsolaeo@yahoo.com; Tel: +2348035067306

Sent for review: 17 January 2017

Revised accepted: 19 April 2017

\begin{abstract}
Purpose: To evaluate the dissolution and permeation characteristics of artemether tablets formulated with cashew and prosopis gums, and compare with tablets prepared with acacia gum.

Methods: Artemether tablets containing varying concentrations (1.0 to $4.0 \% \mathrm{w} / \mathrm{w}$ ) of cashew and prosopis gums or $3 \% \mathrm{w} / \mathrm{w}$ of acacia (control) gum as binders were formulated by wet granulation method. The tablets were evaluated for crushing strength, friability and disintegration time. Dissolution and permeation characteristics of the formulations were studied using USP methods.

Results: Tablets formulated with prosopis gum had higher crushing strength, higher friability and higher disintegration time compared to those of cashew gum at corresponding binder concentrations. Tablets formulated with $3 \% \mathrm{w} / \mathrm{w}$ cashew gum exhibited complete drug release within $1 \mathrm{~h}, 95 \%$ drug permeation in $188 \mathrm{~min}$ (in simulated gastric fluid [SGF]) and $95 \%$ permeation in 224 min (under simulated intestinal fluid [SIF] condition) while those made with $3 \% \mathrm{w} / \mathrm{w}$ prosopis gum exhibited $70.7 \%$ drug release in $1 \mathrm{~h}$, $95 \%$ permeation in $135 \mathrm{~min}$ (in SGF) and $95 \%$ permeation in 170 min (under SIF condition).

Conclusion: Cashew gum is effective as a binder over a relatively wide range of concentrations to achieve fast drug release though with minimal permeation enhancement while prosopis gum is characterized by delayed drug release but enhanced permeation of the released drug.
\end{abstract}

Keywords: Cashew gum, Acacia, Prosopis, Artemether, Drug release, Dissolution, Permeation

Tropical Journal of Pharmaceutical Research is indexed by Science Citation Index (SciSearch), Scopus, International Pharmaceutical Abstract, Chemical Abstracts, Embase, Index Copernicus, EBSCO, African Index Medicus, JournalSeek, Journal Citation Reports/Science Edition, Directory of Open Access Journals (DOAJ), African Journal Online, Bioline International, Open-J-Gate and Pharmacy Abstracts

\section{INTRODUCTION}

The mechanisms by which surface active agents can influence drug delivery vary widely and include micellar solubilization and permeation enhancement [1]. The release of poorly watersoluble drugs from tablets and capsules may be enhanced by the presence of surfactants in their formulations. Increase in saturation solubility of such drugs by solubilization in surfactant micelles might also enhance dissolution and absorption
[2]. Hence, the effect of surface active agents on drug delivery depends on the nature of the drug especially its water solubility. Artemether is a white crystalline powder with good solubility in organic solvents and poor solubility in water [3]. It is a lipid-soluble artemisinin [4].

An earlier study characterized cashew gum (CSG) as having a critical micelle concentration (CMC) of $0.50 \% \mathrm{w} / \mathrm{v}$, capable of reducing the surface tension of water to $55.0 \mathrm{mN} / \mathrm{m}$ and 
having hydrophile-lipophile balance (HLB) value of 16.09 [5]. The surface activity of the polymer was comparable with that of acacia gum. Its FTIR spectrum showed $\mathrm{O}-\mathrm{H}$ bending and $\mathrm{C}-\mathrm{O}$ stretching which are typical of ether and alcohol. It also showed stretching vibration of bonded $\mathrm{O}$ $\mathrm{H}$ group and stretching vibration of free $\mathrm{O}-\mathrm{H}$ [6]. Prosopis gum (PRG) has also been characterized as having two endotherms with peaks at 62 and $300{ }^{\circ} \mathrm{C}$ typical of enthalpy relaxation and melting of the polymer [7]. The characterization showed that the polymer has an HLB value of 11.26 , a CMC of $0.25 \% \% / v$ and capable of reducing the surface tension of water to $55.0 \mathrm{mN} / \mathrm{m}$. Therefore, CSG and PRG have different surface activity.

Compatibility of the two polymers with artemether was investigated in a previous study [7]. The interactions between the drug and the two polymers were examined using differential scanning calorimetry, Fourier transform infrared spectroscopy and powder X-ray diffraction. It was observed that the two polymers had similar effects of reducing the melting point and increasing recrystallization temperature of artemether. Cashew gum caused shifts in the peaks of the FTIR spectrum of artemether while prosopis gum caused reduction in the height of the peaks but no new peak was formed in either of the cases.

Natural gums have been evaluated for pharmaceutical use as binding, suspending and emulsifying agents [8-10]. From the available literature, the surface activity of this class of pharmaceutical excipients had not been related to drug delivery from tablets. This work was aimed at assessing the dissolution and permeation parameters of artemether tablets formulated with cashew and prosopis gum as binders and to consider the relationship between these parameters and surface activity of the gums using acacia gum (ACG) as a reference binder.

\section{EXPERIMENTAL}

\section{Materials}

Crude cashew exudates were collected from Anacardium occidentale $L$. trees in Abuja, Nigeria while seeds of Prosopis africana trees were purchased at Abuja, Nigeria. The two materials were authenticated by Mr Olusegun Olayanju - the taxonomist in the Department of Biological Sciences, University of Abuja, Abuja, Nigeria and issued with voucher nos. UNIABUJA 150 and UNIABUJA 153, respectively as earlier reported $[5,11]$. Other materials used were: artemether powder (Afrab Chem. Ltd, Lagos, Nigeria), Acacia senegal gum (BDH Chemicals, Poole, England), lactose (Surechem Products Limited, England), maize starch B.P. (BDH Chemicals, Poole, England), magnesium stearate (Riedel-De Haen, Germany) and talc (BDH Chemicals, Poole, England).

\section{Ethical approval}

Approval for experimentation involving laboratory animal was obtained from Ethics Committee of the Faculty of Pharmacy, University of Uyo, Uyo, Nigeria (protocol no. UU/PH/002). The animal was housed in a cross-ventilated room and later sacrificed in accordance with internationally accepted laboratory animal use [12] and the guidelines and rules for experimentation involving animals by Canadian Council on Animal Care [13] were followed.

\section{Extraction and purification of the polymers}

Cashew gum was extracted from the exudates of Anacardium occidentale $L$. and purified by applying the method described by Ofori-Kwakye et al [10]. The extraction and purification of prosopis gum were carried out by applying the method described by Adikwu et al [14].

\section{Preparation of tablets}

Using varying concentrations $(1.0,2.0,3.0$ and $4.0 \% \mathrm{w} / \mathrm{w}$ ) of the gum, nine (9) batches of tablets were formulated by wet granulation using the formula in Table 1. The weighed amounts of artemether, maize starch B.P. and lactose sufficient to produce 50 tablets per batch were dry-mixed for a period of $5 \mathrm{~min}$ and then moistened with $2.5 \mathrm{ml}$ mucilage of the binder (CSG, PRG or ACG). The wet mass was sieved through a $2.0 \mathrm{~mm}$ mesh and dried in a hot air oven (Gallenkamp, Germany) at $60 \stackrel{\circ}{ } \mathrm{C}$ for $1 \mathrm{~h}$ [12]. It was subsequently sieved through a 1.0 $\mathrm{mm}$ mesh. The glidant and the lubricant were weighed and gently blended with the dried granules. The granules of uniform weight and containing $20 \mathrm{mg}$ artemether per tablet were compressed into tablets at a pressure of $30 \mathrm{KN}$ using a single punch tableting machine (Erweka, Germany) fitted with $8.0 \mathrm{~mm}$ punches.

\section{Evaluation of tablets}

A period of $24 \mathrm{~h}$ was allowed for all the batches of tablet produced to experience stress relaxation before subjecting them to quality assessment [15]. The tablets were evaluated for crushing strength, friability and disintegration time. 
Table 1: Composition of artemether tablets

\begin{tabular}{|c|c|c|c|c|c|c|c|c|c|}
\hline \multirow{2}{*}{ Ingredient $(\% \mathrm{w} / \mathrm{w})$} & \multicolumn{4}{|c|}{ Cashew gum } & \multicolumn{4}{|c|}{ Prosopis gum } & \multirow{2}{*}{$\begin{array}{c}\begin{array}{c}\text { Acacia } \\
\text { gum }\end{array} \\
\text { IX }\end{array}$} \\
\hline & I & II & III & IV & $\mathbf{V}$ & VI & VII & VIII & \\
\hline Artemether & 7.3 & 7.3 & 7.3 & 7.3 & 7.3 & 7.3 & 7.3 & 7.3 & 7.3 \\
\hline Maize starch BP & 10.0 & 10.0 & 10.0 & 10.0 & 10.0 & 10.0 & 10.0 & 10.0 & 10.0 \\
\hline Lactose & 79.7 & 78.7 & 77.7 & 76.7 & 79.7 & 78.7 & 77.7 & 76.7 & 77.7 \\
\hline Cashew gum (CSG) & 1.0 & 2.0 & 3.0 & 4.0 & - & - & - & - & - \\
\hline Prosopis gum (PRG) & - & - & - & - & 1.0 & 2.0 & 3.0 & 4.0 & - \\
\hline Acacia gum (ACG) & - & - & - & - & - & - & - & - & 3.0 \\
\hline Talc & 1.5 & 1.5 & 1.5 & 1.5 & 1.5 & 1.5 & 1.5 & 1.5 & 1.5 \\
\hline Magnesium stearate & 0.5 & 0.5 & 0.5 & 0.5 & 0.5 & 0.5 & 0.5 & 0.5 & 0.5 \\
\hline
\end{tabular}

\section{Dissolution studies}

The dissolution test was carried out in triplicates using USP dissolution apparatus (Panomex Inc., India). A tablet was placed inside the dry basket of the apparatus and lowered inside the beaker containing $900 \mathrm{ml}$ of $0.1 \mathrm{M}$ hydrochloric acid thermostatically maintained at $37.0 \pm 0.5^{\circ} \mathrm{C}$ [12]. The apparatus was set to a rotational speed of $100 \mathrm{rpm}$ for $2 \mathrm{~h}$. At $20 \mathrm{~min}$ intervals, $10 \mathrm{ml}$ samples were taken with subsequent replacement with equal volume of the dissolution medium. Each sample was filtered with Whatman no. 1 filter paper and diluted with pure dissolution medium. The absorbance was taken at $210 \mathrm{~nm}$ [16] using a UV spectrophotometer (UNICO Shanghai Instrument, China). A graph of cumulative percent drug released was plotted against time [12]. The cumulative percent drug released was calculated using Eqs 1 and 2 .

$C=\frac{A . V f}{s}$

$\%_{D R}=\frac{C_{N} V}{D} X 100 \%$

where $\mathrm{C}$ is the concentration of the cumulative amount of drug released into the dissolution medium at a particular time, $\mathrm{A}$ is the absorbance of the solution, $\mathrm{Df}$ is the dilution factor, $\mathrm{S}$ is the slope of the calibration curve, \%DR is the percent drug released, $\mathrm{V}$ is the volume of the dissolution medium and $D$ is the amount of drug per tablet.

\section{Permeation studies}

Drug permeation studies were carried out with U.S.P. dissolution apparatus (Panomex Inc, India) using the modified method of Sharma et al [17]. Segments of the intestine of freshly sacrificed pig were obtained and used as donor compartments. Each segment was tied at one end and filled with $5 \mathrm{ml}$ of SGF (pH 1.2) or SIF (pH 6.8) produced based on USP $33-N F 28$ [18]. The tablet to be studied was placed inside the donor compartment and the segment was tied at the other end. The donor chamber was subsequently lowered into a dissolution apparatus containing $1,000 \mathrm{ml}$ of the receptor medium of $1.0 \mathrm{M}$ ethanolic hydrochloric acid solution [3]. The temperature of the system was maintained at $37 \pm 0.5^{\circ} \mathrm{C}$. Aliquots of $10 \mathrm{ml}$ were withdrawn at $30 \mathrm{~min}$ intervals from the dissolution medium with replacement using pure medium [12]. Each sample was filtered and $5 \mathrm{ml}$ of the filtrate was diluted with $5 \mathrm{ml}$ of pure medium. The resulting solution was analyzed using a UV spectrophotometer (UNICO Shanghai Instrument, China) at $210 \mathrm{~nm}$. A graph of cumulative percent drug permeated was plotted against time. The cumulative percent drug permeated was calculated in a similar way as cumulative percent drug released stated in Eqs 1 and 2. The time for $95 \%$ drug permeation ( $\mathrm{t}$ 95\%) was taken from the graph. Value of steady state drug flux $(\mathrm{J})$ and permeation coefficient $\left(\mathrm{K}_{\mathrm{p}}\right)$ were calculated using Eqs 3 and 4.

$\mathrm{J}=\frac{d Q}{d t A}$

$K p=\frac{J}{C}$

where $d Q$ is the change in the quantity of drug absorbed, $\mathrm{dt}$ is the change in time, $\mathrm{A}$ is the surface area of the membrane and $C$ is initial concentration of the drug in the donor compartment. The value of $d Q / d t$ was estimated from the gradient of the plot of percent drug permeated versus time.

\section{Statistical analysis}

The data obtained are expressed as mean \pm standard error of the mean (SEM). Statistical analysis was done using one-way analysis of variance (ANOVA) followed by Turkey-Kramer multiple comparison test using GraphPad Instat3 software. Significance of difference was set at $p<0.05$. 
Table 2: Physical properties of the artemether tablets

\begin{tabular}{llccc}
\hline Batch & Code & $\begin{array}{c}\text { CS (kgf) } \\
\mathbf{n = 5}, \pm \text { ISEM }\end{array}$ & $\begin{array}{c}\text { FR (\%) } \\
\mathbf{n = 3}, \pm \text { SEM }\end{array}$ & $\begin{array}{c}\text { DT (min) } \\
\mathbf{n = 6}, \pm \text { SEM }\end{array}$ \\
\hline I & CSG1 & $4.10 \pm 0.89$ & $0.70 \pm 0.01$ & $2.10 \pm 0.06$ \\
II & CSG2 & $4.50 \pm 0.20$ & $0.66 \pm 0.14$ & $2.16 \pm 0.08$ \\
III & CSG3 & $4.60 \pm 0.22$ & $0.58 \pm 0.10$ & $2.24 \pm 0.11$ \\
IV & CSG4 & $5.20 \pm 0.63$ & $0.41 \pm 0.04$ & $2.99 \pm 0.13$ \\
V & PRG1 & $4.50 \pm 0.20$ & $1.41 \pm 0.38$ & $28.98 \pm 0.03$ \\
VI & PRG2 & $4.60 \pm 0.22$ & $0.80 \pm 0.18$ & $37.89 \pm 0.06$ \\
VII & PRG3 & $5.20 \pm 0.11$ & $0.76 \pm 0.06$ & $59.77 \pm 0.45$ \\
VIII & PRG4 & $5.50 \pm 0.00$ & $0.70 \pm 0.00$ & $69.71 \pm 0.33$ \\
IX & ACG3 & $4.60 \pm 0.34$ & $0.92 \pm 0.03$ & $3.23 \pm 0.16$
\end{tabular}

CSG1 $1 \% 1 \%$ w cashew gum; CSG2= $2 \%$ w $/ \mathrm{w}$ cashew gum; CSG3 = $3 \%{ }^{\mathrm{w}} / \mathrm{w}$ cashew gum; CSG4= $4 \%{ }^{\mathrm{w}} / \mathrm{w}$ cashew gum; PRG1 $1 \% 1 \%$ w prosopis gum; PRG2 = $2 \%$ w $/ \mathrm{w}$ prosopis gum; PRG3= $3 \%$ w $/ \mathrm{w}$ prosopis gum; PRG4 $=4 \% \mathrm{w} / \mathrm{w}$ prosopis gum; ACG3 $=3 \% \mathrm{w} / \mathrm{w}$ acacia gum

\section{RESULTS}

\section{Physical properties of the tablets}

The physical properties of tablets containing different binder concentrations are shown in Table 2. Tablets containing PRG had higher crushing strength, higher friability and longer disintegration time at all binder concentrations used compared to those containing CSG.

\section{Dissolution profile}

The dissolution plots of tablets containing $3 \% \mathrm{w} / \mathrm{w}$ for the different gums are illustrated in Figure 1. Batches containing CSG and ACG gave complete drug release within $1 \mathrm{~h}$ while the batch containing PRG gave $70.7 \%$ drug release within the same period.

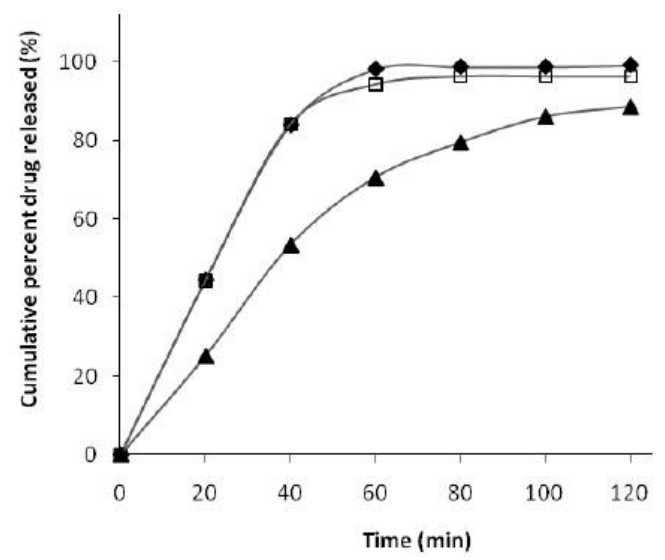

Figure 1: Dissolution profile of tablets containing 3 $\%$ w/w gum as binder. Key: CSG3 (), PRG3 (4), ACG3 $(\bullet)$

\section{Permeation profile in simulated gastric fluid}

The plots of cumulative percent drug permeated under SGF condition versus time of permeation for tablets containing different gum concentrations are shown in Figure 2 and the permeability data are shown in Table 3 . While there was no significant difference in drug flux from tablets containing $3 \% \mathrm{w} / \mathrm{w}$ ACG and $3 \% \mathrm{w} / \mathrm{w}$ CSG, tablets containing the same concentration of PRG exhibited significantly higher drug flux. The quantity of drug permeated in $30 \mathrm{~min}$ decreased with increase in concentration of PRG but the time for $95 \%$ drug permeation was not significantly different. Drug flux at steady state varied directly with concentration of the polymer.

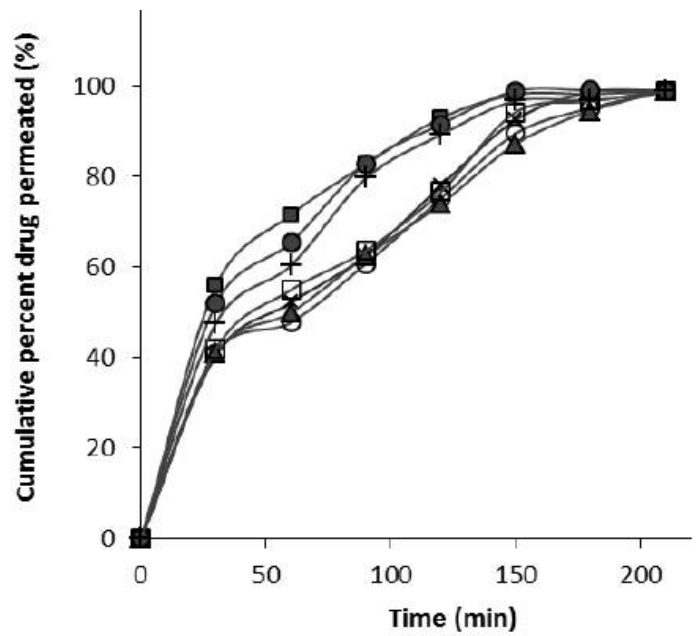

Figure 2: Permeation profile of artemether in simulated gastric fluid (SGF) for tablets containing different gum concentrations. Key: CSG2 (x), CSG3

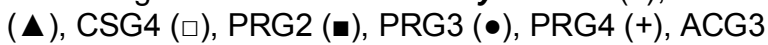
(o)

\section{Permeation profile in simulated intestinal fluid}

The plot of cumulative percent drug permeated under SIF condition versus time of permeation for tablets containing different gum concentrations are shown in Figure 3 and the 
Table 3: Permeability data of artemether tablets in simulated gastric fluid (SGF)

\begin{tabular}{|c|c|c|c|c|}
\hline Batch & Code & $\begin{array}{l}\text { Drug flux } \\
\left(\mu \mathrm{g} / \mathrm{cm}^{2} . \mathrm{s}\right)\end{array}$ & $\begin{array}{c}\text { Permeation } \\
\text { coefficient } \\
\times 10^{-6}(\mathrm{~cm} / \mathrm{s})\end{array}$ & $\begin{array}{l}\text { Time for } 95 \% \\
\text { permeation } \\
\text { (min) }\end{array}$ \\
\hline II & CSG2 & $0.092 \pm 0.03$ & $23.00 \pm 6.95$ & 162 \\
\hline III & CSG3 & $0.093 \pm 0.02$ & $23.18 \pm 4.82$ & 188 \\
\hline IV & CSG4 & $0.090 \pm 0.01$ & $22.42 \pm 2.18$ & 190 \\
\hline VI & PRG2 & $0.092 \pm 0.01$ & $23.08 \pm 2.22$ & 133 \\
\hline VII & PRG3 & $0.103 \pm 0.02$ & $25.68 \pm 5.68$ & 135 \\
\hline VIII & PRG4 & $0.113 \pm 0.01$ & $28.25 \pm 3.50$ & 136 \\
\hline IX & ACG3 & $0.094 \pm 0.02$ & $23.50 \pm 4.84$ & 179 \\
\hline
\end{tabular}

Data are mean \pm SEM $(n=3) ; C S G 2=2 \%{ }^{w} / w$ cashew gum;CSG3 $=3 \%{ }^{w} / w$ cashew gum; CSG4 $=4 \%{ }^{w} / w$ cashew gum; PRG2 $=2 \% \mathrm{w} / \mathrm{w}$ prosopis gum; PRG3 $=3 \% \mathrm{w} / \mathrm{w}$ prosopis gum; PRG4 $=4 \% \mathrm{w} / \mathrm{w}$ prosopis gum; ACG3 $=3 \%{ }^{w} / w$ acacia gum

Table 4: Permeability data of the artemether tablets in simulated intestinal fluid (SIF)

\begin{tabular}{|c|c|c|c|c|}
\hline Batch & Code & $\begin{array}{c}\text { Drug flux } \\
\left(\mu \mathrm{g} / \mathrm{cm}^{2} . \mathrm{s}\right)\end{array}$ & $\begin{array}{c}\text { Permeation } \\
\text { coefficient } \\
\times 10^{-6}(\mathrm{~cm} / \mathrm{s})\end{array}$ & $\begin{array}{l}\text { Time for } 95 \% \\
\text { permeation } \\
\text { (min) }\end{array}$ \\
\hline II & CSG2 & $0.097 \pm 0.02$ & $24.25 \pm 4.50$ & 220 \\
\hline III & CSG3 & $0.103 \pm 0.01$ & $25.75 \pm 1.75$ & 224 \\
\hline IV & CSG4 & $0.110 \pm 0.05$ & $27.50 \pm 1.25$ & 224 \\
\hline VI & PRG2 & $0.103 \pm 0.02$ & $25.75 \pm 5.50$ & 169 \\
\hline VII & PRG3 & $0.113 \pm 0.02$ & $28.25 \pm 5.75$ & 170 \\
\hline VIII & PRG4 & $0.129 \pm 0.03$ & $32.25 \pm 7.25$ & 170 \\
\hline IX & ACG3 & $0.102 \pm 0.02$ & $25.50 \pm 4.00$ & 223 \\
\hline
\end{tabular}

Data are mean \pm SEM $(n=3) ;$ CSG2 $=2 \%{ }^{w} / w$ cashew gum; CSG3 $=3 \%{ }^{w} / w$ cashew gum; CSG4 $=4 \%{ }^{w} / w$ cashew gum; PRG2 $=2 \%$ w/w prosopis gum; PRG3 $=3 \%$ w $/ w$ prosopis gum; PRG4 = $4 \%$ w $/ w$ prosopis gum; ACG3 $=3 \%$ w $/ w$ acacia gum

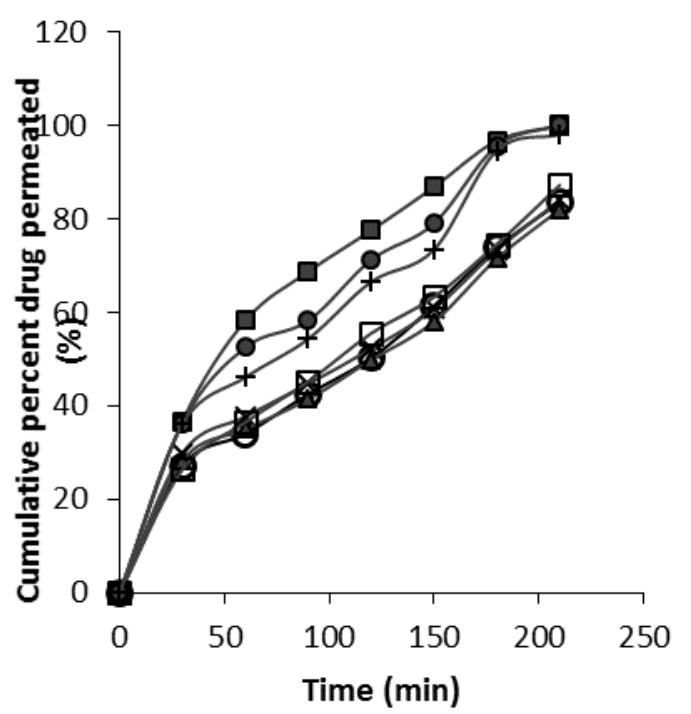

Figure 3: Permeation profile of artemether in simulated intestinal fluid (SIF) for tablets containing different gum concentrations. Key: CSG2 (x), CSG3

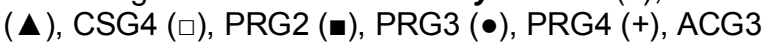
(o)

permeability data are shown in Table 4. There was no significant difference in drug flux from tablets containing $3 \% \mathrm{w} / \mathrm{w}$ ACG and $3 \% \mathrm{w} / \mathrm{w}$ CSG while tablets containing the same concentration of PRG exhibited higher drug flux at steady state. There was no significant difference in $\mathrm{t}$ 95\% for tablets containing different concentrations of CSG. The permeation coefficient varied directly with concentration of PRG.

\section{DISCUSSION}

Tablets containing CSG had lower crushing strength and lower friability compared to those containing PRG at all the binder concentrations used. It can thus be inferred that CSG confers less resistance to crushing but more resistance to abrasion. Conversely, PRG confers more resistance to crushing and less resistance to abrasion. This observation is similar to that which was reported by Alebiowu and Itiola [15] where tablets containing native plantain starch had higher tensile strength and higher brittle fracture index compared to native sorghum starch.

Tablet strength is directly related to the magnitude of plastic deformation taking place during compression [19]. Therefore, PRG experienced higher amount of plastic deformation compared to CSG as tablets containing PRG had higher crushing strength at all the binder concentrations used. A tablet is expected to have a friability of less than $1 \%$ to pass quality assessment test [20]. All the tablets 
containing different concentrations of CSG passed the test for friability. For tablets containing different concentrations of PRG, all but the batch containing $1 \% \mathrm{w} / \mathrm{w}$ of the binder passed the test for friability. Hence, binder concentration of $1 \% \mathrm{w} / \mathrm{w}$ was excluded from dissolution and permeation studies.

An immediate-release tablet is expected to have disintegration time of less than 15 min to pass quality assessment test [21]. All the tablets containing CSG as binder passed the test while those containing PRG failed the test. The long disintegration time of tablets containing $P R G$ suggests that the polymer could be investigated for sustained or controlled delivery of drugs.

The concentration of the standard gum used was $3 \% \mathrm{w} / \mathrm{w}$. Hence, this concentration was chosen for the dissolution studies of the test gums. Since tablet disintegration precedes drug dissolution, the trend of dissolution in relation to concentration is likely to follow that of disintegration.

For an immediate-release tablet to pass dissolution test, a minimum of $75 \%$ of the drug must be released within $1 \mathrm{~h}$ [21]. Tablets containing $3 \% \mathrm{w} / \mathrm{w}$ CSG passed the test for dissolution whereas those containing the same concentration of PRG failed the test. Therefore, prosopis gum at concentration up to $3 \% \mathrm{w} / \mathrm{w}$ is not suitable for the formulation of immediaterelease tablets.

Cashew gum has an HLB value of 16.09 [5] which is within the range for surfactants having solubilizing property [22]. Therefore, the short disintegration time of artemether tablets containing the gum can be attributed to fast hydration of the gum; and the fast dissolution rate can be linked to the surface activity and high HLB value of the gum. All the concentrations of CSG used are suitable for formulation of artemether into immediate-release tablets.

The slow dissolution rate of tablets containing PRG is related to the long disintegration time. The slow rate can be linked to the high binding strength of the polymer as reported by Attama et al [23]. It can also be explained by the poorer hydrophilicity compared to CSG. PRG has a lower HLB value of 11.26 [11]. The long dissolution time of tablets containing PRG and the ability of the polymer to form hydrogel which is typical of hemicelluloses [24] suggest the suitability of the gum for controlled-release formulations.
For permeation under simulated gastric fluid condition, no significant difference in permeation coefficient was observed with tablets containing different concentrations of CSG. Since all the tablets containing the gum as binder disintegrated within $3 \mathrm{~min}$, the drug was made available for dissolution and absorption in relatively short time. Disintegration is the first step of drug release from tablets; and it plays an important role in the dissolution process [9]. Hence, there was no significant difference in the time taken for $95 \%$ drug permeation from tablets containing different concentrations of the polymer under simulated gastric fluid condition. According to Suputtamongkol et al [25], artemether attains peak plasma concentration in $2 \mathrm{~h}$; and may undergo complete absorption within $4 \mathrm{~h}$. Cashew gum has a mild permeation enhancing effect on the drug as it reduced the $t 95 \%$ to an average of 3 h. The mild permeation enhancing effect of the polymer is evident by the high CMC of $0.50 \% \mathrm{w} / \mathrm{v}$ and its ability to reduce the surface tension of water to $55.0 \mathrm{mN} / \mathrm{m}$ [5].

The increase in drug flux at steady state and increase in the permeation coefficient with increase in the concentration of PRG shows that the polymer enhances the permeation of the artemether through biological membrane under SGF condition. Prosopis gum has a lower CMC of $0.25 \% \mathrm{w} / \mathrm{v}$ [11], a property which is necessary for good surface activity. It is thus obvious that while CSG has a better drug releasing property, PRG has a better permeation enhancing effect on the released drug when they are used as binders for the lipid-soluble, poorly water-soluble artemisinin.

There was increase in the permeation coefficient of artemether with increase in the concentration of CSG. The permeation coefficient under the simulated intestinal fluid condition is higher than that of simulated gastric fluid condition. Therefore, artemether is more permeable at higher $\mathrm{pH}$ and/or increase in $\mathrm{pH}$ favours surface activity of cashew gum. Change in $\mathrm{pH}$ had similar effect on permeation of artemether for the drug formulated with acacia and cashew gums.

The increase in permeation coefficient of the drug with increase in the concentration of PRG can be ascribed to decline in interfacial tension with increase in the concentration of the surface active prosopis gum. The eventual time taken for $95 \%$ drug permeation was however, not affected by increase in the concentration of the gum. This is sequel to the dual action of the gum (as a binder and as a surface active agent). The 
permeation coefficient under SIF condition is higher than SGF condition. The same deduction given for formulations containing cashew gum is applicable to this. The observation can also be attributed to increase in solubility of hemicellulosic gums (such as afzelia gum and prosopis gum) with increase in $\mathrm{pH}$ [24].

Surface active agents are capable of temporarily increasing membrane permeability [1]. Hence, the ability of CSG and PRG to reduce the surface tension of water from $72 \mathrm{mN} / \mathrm{m}$ to $55 \mathrm{mN} / \mathrm{m}$ (surface activity) can be linked to their permeation enhancement. Prosopis gum has additional qualities of lower HLB value and higher bioadhesive strength [22] enabling the drug to have better contact with the biological membrane. This explains why PRG had a better permeation enhancing ability.

\section{CONCLUSION}

Cashew gum is similar to acacia gum in terms of binding, release and permeation-enabling properties. It is characterized by good drug release and minimal permeation enhancement. Prosopis gum has a good permeation enhancing effect on artemether but high concentration of the polymer is characterized by delayed drug release.

The higher HLB value of cashew gum favours the drug dissolution while the lower HLB value, lower CMC and higher bioadhesive strength of prosopis gum favour the permeation of the lipidsoluble artemisinin. The drug dissolution and permeation are influenced by the surface activity of the two gums.

\section{DECLARATIONS}

\section{Acknowledgement}

The authors are grateful to the Management of University of Uyo for the research grant given to Emmanuel Olorunsola to undertake this research.

\section{Conflict of Interest}

No conflict of interest associated with this work.

\section{Contribution of Authors}

The authors declare that this work was done by the authors named in this article and all liabilities pertaining to claims relating to the content of this article will be borne by them.

\section{Open Access}

This is an Open Access article that uses a funding model which does not charge readers or their institutions for access and distributed under the terms of the Creative Commons Attribution License (http://creativecommons.org/licenses/by/ 4.0) and the Budapest Open Access Initiative (http://www.budapestopenaccessinitiative.org/rea d), which permit unrestricted use, distribution, and reproduction in any medium, provided the original work is properly credited.

\section{REFERENCES}

1. Ashford M. Bioavailability - physicochemical and dosage form factors. In: Aulton, Michael E., editor. The Design and Manufacture of Medicine. 3rd ed. Hungary: Churchill Livingstone Elsevier; 2007; pp 286-323.

2. Rangel-Yagui CO, Junior AP, Tavares LC. Micellar solubilization of drugs. J Pharm Pharm Sci 2005; 8(2): 147-163.

3. International Pharmacopoeia. World Health Organization Publication: 2006. p. 988-994.

4. Rosenthal PJ. Antiprotozoal drugs. In: Katzung, Bertram G., editor. Basic and Clinical Pharmacology. 9th edn, Singapore: The McGraw-Hill Companies Inc.; 2004. p. 864-885.

5. Olorunsola EO, Bhatia PG, Tytler BA, Adikwu MU. Surface activity and hydrophile-lipophile balance of hydrophilic polymers from exudates of cashew and khaya plants. Int J Biol Pharm Res 2014; 5(5): 443-448.

6. Coutts RT. Infrared spectroscopy. In: Chatten, Leslie G., editor. Pharmaceutical Chemistry - Instrumental Techniques. New Delhi, India: CBS Publishers and Distributors PVT Ltd.; 2008. p. 59-125.

7. Olorunsola EO, Bhatia PG, Tytler BA, Adikwu MU. Compatibility study of cashew and prosopis gums with some artemisinin derivatives. Nig J Pharm 2016; 50(2): 35-53.

8. Abdulsamad A, Bhatia PG, Ojile JE. Emulsifying and suspending properties of cashew gum. Nig J Pharm Res 2006; 5(1): 40-47.

9. Ibezim EC, Khanna M, Singh S, Uzuegbunam CE. Afzelia africana seed gum: potential binder for tablet formulations. J Phytomed Therap 2006; 11: 38-48.

10. Ofori-Kwakye K, Asantewaa Y, Kipo SL. Physicochemical and binding properties of cashew tree gum in metronidazole tablet formulation. Int $J$ Pharm Pharm Sci 2010; 2(4): 105-109.

11. Olorunsola EO, Bhatia PG, Tytler BA, Adikwu MU. Physicosurface properties of afzelia and prosopis hemicellulosic gums: potential surface active agents. IOSR J Pharm Biol Sci 2015; 10(4 version 3): 1-7.

12. Olorunsola EO, Uwah TO, Olayemi OJ, Etukudo UB. Exvivo evaluation of crab shell chitosan as absorption enhancer in ciprofloxacin tablet formulation. Afr $J$ Biotechnol 2016; 15(36): 1930-1935. 
13. CCAC policy statement on ethics of animal investigation. Canadian Council on Animal Care, 1989 [cited 2017 Mar 15]. Available from: www.ccac.ca

14. Adikwu MU, Yoshikwa Y, Kanji T. Bioadhesive delivery of metformin using prosopis gum with antidiabetic potential. Biol Pharm Bull 2003; 26(5): 662 - 666.

15. Alebiowu AG, Itiola OA. Effect of starches on mechanical properties of paracetamol formulation. Acta Pharm 2003; 53: 231-232.

16. United States Pharmacopoeial Medicines Compendium, 2013 [cited 2013 Aug 24]. Available from: http://mc.usp.org.

17. Sharma N, Kulkarni GT, Sharma A. Development of novel Abelmoschus esculentus (Okra) gel for nasal delivery of rizatriptan benzoate. Trop $J$ Pharm Res 2013; 12(2): 149-153.

18. United States Pharmacopoeia 33 - NF 28, 2010 [cited 2016 Nov 04]. Available from: http://www.usp.org.

19. Uhumwangho MU, Okor RS, Eichie FE, Abbah CM. Influences of some starches on the brittle fracture tendency of paracetamol tablets. Afr J Biotechnol 2006; 5(20): 1950-1953.
20. Remington JP, Troy $D B$, Beringer $P$. Remington - The Science and Practice of Pharmacy. Philadelphia: Lippincott Williams and Wilkins; 2006.

21. United States Pharmacopoeia 31 - NF 26, 2008 [cited 2013 Sept 12]. Available from: http:// www.uspnf.com.

22. Davies JT. A quantitative kinetic theory of emulsion type 1: Physical chemistry of the emulsifying agent. Proceedings of Second International Congress on Surface Activity. Butterworths, London; 1957. p. 426438.

23. Attama AA, Adikwu MU, Okoli N. Studies in bioadhesive granules 1: Granules formulated with Prosopis africana gum. Chem Pharm Bull 2000; 48(5): 734-737.

24. Builders PF, Chukwu C, Obidike I, Builders MI, Attama $A A$, Adikwu MU. A novel xyloglucan gum from seeds of Afzelia africana Se. Pers.: Some functional and Physicochemical properties. Int J Green Pharm 2009; 3(2): 112-118.

25. Suputtamongkol $Y$, Newton PN, Angus B, TejaIsavadharm $P$, Keeratithakul $D$, Rasameesoraj $M$, Pukrittayakamee S, White NJ. A comparison of oral artesunate and artemether antimalarial bioactivities in acute falciparum malaria. Bri J Cli Pharmacol 2001; 52(6): 655-661. 